\section{B A Institute of \\ YK Business Administration \\ TK \\ Karachi \\ Leadership and Ideas for Tomorrow}

Business Review

Volume 13 Issue 1 January-June 2018

6-14-2018

\title{
Enhanced understanding of purchase intentions in the context of car buying: Implications for academics and practitioners
}

\author{
Wajid Hussian Rizvi \\ Institute of Business Administration, Karachi, Pakistan \\ Salman Bashir Memon \\ Institute of Business Administration, Karachi, Pakistan \\ Huma Amir \\ Institute of Business Administration, Karachi, Pakistan
}

Follow this and additional works at: https://ir.iba.edu.pk/businessreview

\section{(c) (9)}

This work is licensed under a Creative Commons Attribution 4.0 International License.

\section{Recommended Citation}

Rizvi, W. H., Memon, S. B., \& Amir, H. (2018). Enhanced understanding of purchase intentions in the context of car buying: Implications for academics and practitioners. Business Review, 13(1), 52-68. Retrieved from https://doi.org/10.54784/1990-6587.1037 


\title{
Enhanced understanding of purchase intentions in the context of car buying: Implications for academics and practitioners
}

\author{
Wajid Hussain Rizvi · Salman Bashir \\ Memon - Huma Amir
}

\begin{abstract}
This paper examines the factors that influence purchase intentions in the car buying context. Product attributes such as comfort level, brand name, affordability, resale value, serviceability, color, fuel efficiency, interior, entertainment and safety features are used to determine purchase preference. The results suggest that perceived behavioral control and attitude are major predictors of purchase intentions. Also a comparison of Toyota Vitz and Suzuki Swift reveals greater preference for the Vitz over the Swift.
\end{abstract}

Keywords Purchase intentions - Attitude - Car attributes - Behavioral control.

\section{Introduction}

Strategic marketing revolves around understanding of buying behavior. Business organizations must focus on providing what customers want, and for this purpose it is imperative to develop an understanding of the preference pattern of target consumers. However both practitioners and academics agree that predicting actual customer behavior is a complicated and challenging task. Accomplishment of this task requires the specification of an appropriate model that can predict purchase intentions and identification of the main product attributes that may lead to brand preference.

The appropriateness of a theoretical model largely depends on the type of the product: high involvement products (like cars) require higher order cognitive progression or a careful thinking process to evaluate the overall features and performance of the product. One of the theories that offers a model involving

\footnotetext{
Wajid Hussain Rizvi

Institute of Business Administration, University Road, Karachi-Pakistan

E-mail: wrizvi@iba.edu.pk

Salman Bashir Memon

Institute of Business Administration, University Road, Karachi-Pakistan

Huma Amir

Institute of Business Administration, University Road, Karachi-Pakistan
} 
high order cognition and careful evaluation is the Theory of Planned Behavior or TPB (Ajzen 1985, 1991). As stated in the theory, consumer beliefs about the outcomes of an action, their attitude towards the particular behavioral action, their perceptions of the opinions of their significant others, and their perception of the amount of control they have over the action shape their intention to act.

All of these constructs of the TPB have been studied and extensively applied by many researchers for predicting behavioral intentions (Sheppard et al 1988) in various contexts. These contexts include sustainable food consumption (Vermeir and Verbeke 2006), the intention to use electric cars (Moons and De Pelsmacker 2012), intention to patronize green hotels (Chen and Tung 2014), and organic food consumption (Chen 2007).

This study replicates this model in the context of car buying in the Pakistani market. Car purchase is an example of a high involvement purchase process. Replication studies are very important from a methodological perspective to affirm the efficacy of the model across different contexts. However, a model based approach does not fully capture differences across different markets in terms of their product attribute preferences.

Marketers who are involved in the introduction or launch of any product need to understand consumer preferences in order to predict the behavior of target consumers. It is generally assumed that product performance is assessed by overall perceived quality. However, it is argued here that overall perceived quality is not sufficient to assess product performance, it is important to determine customized perceived quality based on product attributes (Wang et al 2016).

Every product has certain perceived attributes which must be observed and studied individually so that the target market can be captured more effectively and efficiently. For this research the automotive industry has been selected for observing this behavior. Companies in the highly competitive automotive industry find it very challenging to compete only on the basis of vehicle price. Hence, they strive to create a competitive advantage based on features and attributes that could establish their superiority over others.

This study identifies the major preferred attributes of a car (the product) that are used by consumers to assess product performance. The most important product attributes that influence behavioral intentions within the Pakistani car buying context are identified. The impact of these attributes on consumer attitude and purchase intentions is then assessed. Furthermore, this study provides a comparative analysis dashboard for practitioners to assess the position of a particular brand within the identified attributes.

The authors demonstrate a relationship between the attributes of a product and the consumer attitude which translates into an intent to purchase and finally leads to actual buying behavior. No study in the context of Pakistan has identified the most important attributes in the context of a car purchase. This study contributes to literature on consumer purchase decisions by identifying the major preferred attributes of a car. In addition to that, it provides insights for practitioners through a comparative analysis dashboard of the two brands. 


\section{Background and hypotheses development}

Theory of planned behavior (TPB), proposed by Ajzen (1991) postulates that the purchase intentions of a consumer are influenced by consumers' beliefs and attitudes, intentions, and ultimate behavior. The theory has been verified and tested under different contexts and on a vast array of purchase intentions and buying behaviors (Godin and Kok 1996; Sutton et al 1998).

TPB is a modified version of the Theory of Reasoned Actions (TRA), also proposed by Ajzen and Fishbein (1970), which suggests that if an individual regards a behavior favorably (attitude) and believes that significant people in his social circle would approve of him performing that behavior (subjective norms), then his intention (motivation) to perform that action will be strong and, consequently, it is highly likely that the person will engage in that action (behavior).

Conversely, negative personal attitude and disdain from noteworthy peers would result in a low motivation to perform that action and unlikelihood of ultimate behavior. In this context, attitude is the personal disposition (positive or negative) or evaluation that arises when an individual encounters a certain event or object (Eagly and Chaiken 1993; Fazio 1990).

TPB, the modified version of TRA, takes into account TRA's limitation of incomplete volitional control Ajzen (1991) and includes an additional component of perceived behavioral control or PBC (1985). PBC defines the perceived amount of volition, or a consumer's own evaluation of the extent of power he/she has in order to act out the specific behavior and perceived possible difficulties in performing it (Ajzen 1991). It proposes that the individual rationally considers the consequences of any action he intends to undertake before committing himself to the final act or behavior (Ramayah et al 2012).

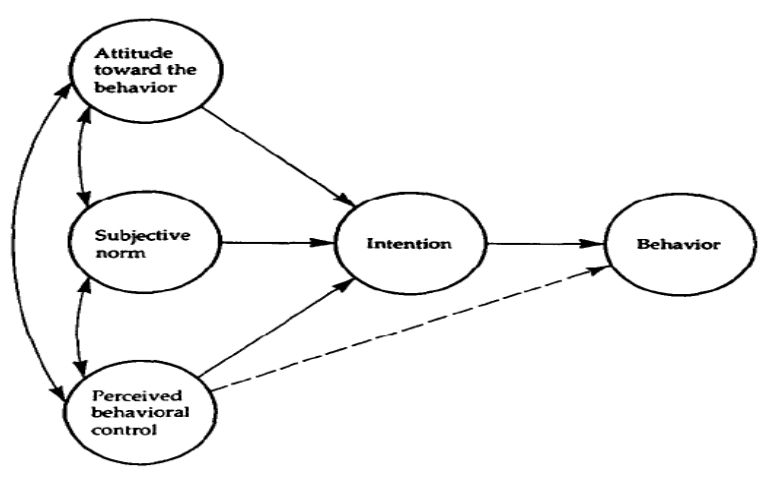

Fig 1: Theory of Planned Behavior Source: Ajzen, 1991 


\subsection{Attitude and intentions}

Academic literature provides sufficient proof of the influence of personal attitude towards a product on the intention to purchase (Fishbein and Ajzen 1975; Boateng and Okoe 2015). A favorable attitude strengthens the intention to execute a behavior and, therefore, attitude can be a strong predictor and antecedent of behavioral intention (Ajzen 1991). Although this claim has met with its due share of criticism from researchers like Wicker (1997) showing that attitude is a weak predictor of intentions Morwitz et al (2014), a number of studies have concluded that consumers' attitude provides a strong impetus for purchase intention (Chaniotakis et al 2010; Tarkiainen and Sundqvist 2005; Povey et al 2000; Armitage and Conner 2001; Chen 2007).

This view is further supported by numerous other studies (Arvola et al 2008; Kotchen and Reiling 2000; Biel and Thøgersen 2007; Gracia Royo and Magistris 2007). In their study on electrical cars, Moons and De Pelsmacker (2015) confirmed a significant positive relationship between attitude and purchase intention. It is proposed here that such a relationship may also be established in the case of hatchback cars. Consumers having a positive attitude towards a specific hatchback car, in comparison with any other car in the category, might also exhibit higher purchase intentions towards that car.

Laroche et al (1996) claimed that the intention to purchase a brand is developed by attitude towards the same brand in relation to other competing brands present in the consideration set. Similarly, in the context of electric hybrid cars, results of various studies Moons and De Pelsmacker (2012) Wang et al (2016) suggest that attitude significantly and positively affects purchase intention. Therefore, we hypothesize:

H1: Attitude has a positive relationship with purchase intentions for hatchback cars.

\subsection{Subjective norms and intentions}

While consumers formulate personal attitudes about products and brands which positively impact intention, their intention to purchase is also influenced by attitudes of others in their social circle towards the intended behavior. Literature shows that social influences positively impact consumers' intentions to purchase products (Jayaraman et al 2018).

Subjective norms, defined as the influence of the opinion of significant others (Ajzen 1991; Al-Swidi et al 2014), have aroused the interest of researchers who have shown that, in general, consumers consider the opinions of their significant others to play a vital role in creating purchase intentions (Ham et al 2015). Scholars Brown et al (2003), have concluded that subjective norms and purchase intentions are significantly positively related in various contexts, for instance, technology use intentions (White Baker et al 2007), green hotel revisits (Han et al 2010) and organic food (Dean et al 2012).

Moreover, Wang et al (2016) have also supported this relationship in their study on electric hybrid cars. This paper proposes that this relationship could 


\section{W. Rizvi et al}

also exist in the case of hatchback cars. The perception in a consumer's mind about the attributes of the car might be influenced by subjective norms which further affect purchase intention. Consequently, hypothesis H2 is recommended as:

H2: Subjective norms have a positive relationship with purchase intentions for hatchback cars.

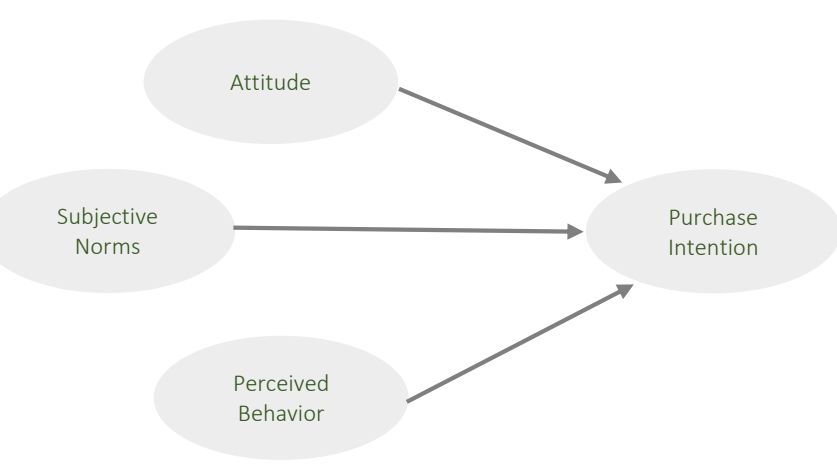

Fig 2: Proposed model

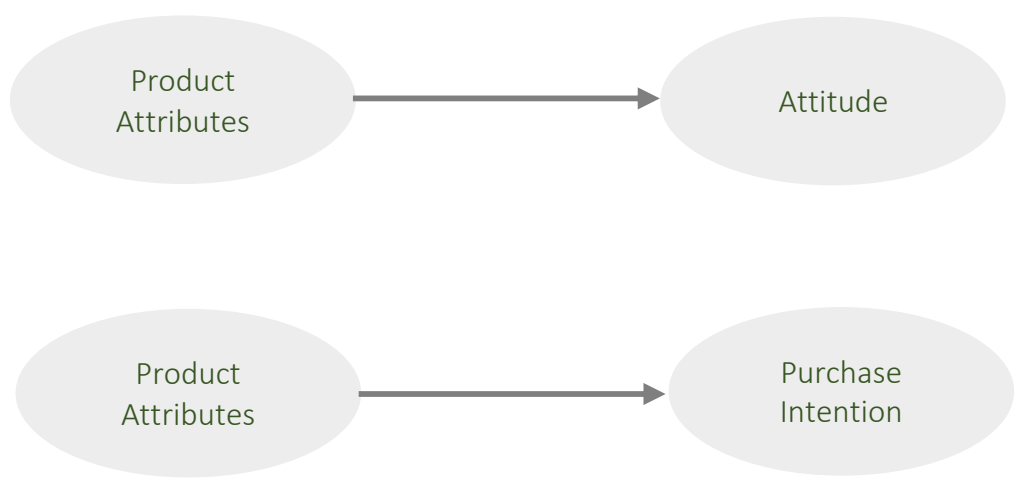

Fig 3: Proposed alternate models

2.3 Perceived behavioral control and intentions

As per Ajzen (1991) the magnitude of the relationship between Perceived Behavioral Control (PBC) and intention is dependent on the type of behavior and 
situation. However, a number of empirical studies show a significant positive relationship with purchase intention, or the purchase behavior when an individual is confident that he/she holds sufficient amount of power and ability to perform the act (Ajzen 1991; White Baker et al 2007; Sparks and Shepherd 1992; Taylor and Todd 1995; Terry and O'Leary 1995).

In the same vein, Sheppard et al (1988) showed that behavior is intensely affected by the confidence people have in how capable they are of performing that action. In Lynne et al.'s study (1995), perceived behavioral controls were able to improve the prediction of actual behavior towards adoption of conservation technology. Moreover, Moons and De Pelsmacker (2012) have also proposed a positive relationship between perceived behavioral controls and purchase intention in their study on electrical cars. Therefore, we can hypothesize that: H3: Perceived behavioral control has a positive relationship with purchase intentions for hatchback cars.

2.4 Relationship between perceived attributes and attitude towards the product

Attributes of a product are its characteristics and features. Several researchers have found a relationship between attributes of a product and consumers' attitudes. According to Kinnear and Taylor (1996), consumer attitude is the likeness or preference towards the product's attribute which abridges the criteria the consumer sets to make buying decisions.

Similarly, Rosenberg (1956) and Fishbein and Ajzen (1975) suggested that attitudes towards a product are based on consumers' perceptions of their attributes. According to Sheth's model $(1969,1971,1974)$ consumers' attitude towards a product is a function of perceived brand potential to satisfy consumers' needs and wants, while the perceived brand potential is the perceived attributes of the product which fulfill consumers' needs and desires (Tuncalp and Sheth, 2013). On the basis of the above mentioned literature, hypothesis $\mathrm{H} 4$ is suggested as:

H4: Perceived attributes of a product have a positive relationship with the consumer attitude towards the product.

\subsection{Relationship between perceived attributes and purchase intentions}

Purchase intentions are strongly influenced by the attributes of a product (Schuitema and De Groot 2015; Rimal et al 2001). In their study on consumer behavior in car purchasing, Lebeau et al (2012) noted that various attributes of cars give rise to purchase intentions among consumers.

Furthermore, Lee and Trail (2012) have equated perceived value of a product to perceived product attributes. Therefore, we can conclude that if perceived quality and perceived value affect purchase intentions, as observed by Monroe and Krishnan (1985), perceived attributes of the product could also affect purchase intentions. Thus, it is hypothesized that:

H5: Perceived attributes of a product positively affect purchase intention. 


\section{Methodology}

This paper employs both qualitative and quantitative methods. The qualitative study was used to elicit customized car attributes. The quantitative study was used to affirm the existing model and the alternative models using the customized attributes.

\subsection{Qualitative study}

Six in-depth interviews were conducted for the exploratory phase of the research. Table 1 itemizes participant details. Three participants were female and three participants were male subject to a filter of low moderate and high driving expertise. Three focus group sessions were carried out. Table 2 shows

Table 1: In-depth interview participants

\begin{tabular}{lcccc}
\hline Code & Gender & Location & Filter-expertise & Type \\
\hline IIML01 & Male & Karachi & Low & In-depth interview \\
IIMM02 & Male & Karachi & Moderate & In-depth interview \\
IIMH03 & Male & Karachi & High & In-depth interview \\
IIFL04 & Female & Karachi & Low & In-depth interview \\
IIFM05 & Female & Karachi & Moderate & In-depth interview \\
IIFH06 & Female & Karachi & High & In-depth interview \\
\hline
\end{tabular}

the focus group details. In each group there were seven participants. Driving expertise (low, moderate and high) was used as a filter in each focus group.

This facilitated in unearthing the possible attributes consumers look for in

Table 2: Focus group participants

\begin{tabular}{ccccc}
\hline Code & No of participants & Location & Filter-expertise & Type \\
\hline FGL01 & 7 & Karachi & Low & Focus group \\
FGM02 & 7 & Karachi & Moderate & Focus group \\
FGH03 & 7 & Karachi & High & Focus group \\
\hline
\end{tabular}

a car and their respective importance to individual consumers. This estimate is closer to country driver statistics. Both male and female drivers were included in the focus groups, with a proportionately larger number of males as compared to females.

Before the interview, all participants were informed about the scope, purpose, and likely implications of the study. In addition, intense care was taken to engage specifically those consumers who had experience with either Vitz or Swift, or both, so that product attributes relevant to the specific product category could be extracted.

Based on the focus groups and in-depth interviews, 13 attributes were elicited of which two attributes, driving pleasure and psychological comfort were dropped 
based on expert opinion. The remaining 11 attributes were used in models and comparative studies. The elicited attributes include: comfort level (material), brand name, affordability, resale value, serviceability (parts availability), color, fuel efficiency, interior, entertainment features and safety features. For comparative study the respondents were asked how important that particular attribute is for the product category and then they were asked to specify if that particular attribute exists in the brand (i.e. Vitz and Swift).

\subsection{Quantitative study}

The data for the quantitative surveys was collected at mall intercepts and car showrooms. Around 700 potential respondents were approached, 245 respondents filled the survey, of which 222 responses were useable. The scale chosen to measure attributes was a balanced Likert scale, having extremes at 1 and 10 ( $1=$ strongly disagree $10=$ strongly agree $)$.

Attitude was measured through the semantic differential scale of 5 items from 1 to 7 (Vermeir and Verbeke 2006). Perceived behavioral control was measured through a Likert scale of 3 items from 1 to 7 (strongly disagree to strongly agree) (Ajzen \& Madden, 1986). Similarly, purchase intention was measured through a Likert scale of 3 items from 1 to 7 (strongly disagree to strongly agree) (Baker \& Churchill, 1977). Subjective norms were measured through a 7 point Likert scale as suggested by Vermeir and Verbeke (2006) from strongly disagree to strongly agree.

11 attributes emerged from exploratory research based on focus groups and in-depth interviews. These were size, easy of parking, comfort level, affordability, resale value, after sale serviceability, color, fuel efficiency, interior, brand name, entertainment features and safety. These attributes were then tested in the conclusive part of the research.

Rigorous quantitative analysis was conducted to analyze the data. The demographic profile results summarized in table 1 are followed by the test of dimensionality (i.e. factor analysis), internal consistency (i.e. reliability), pairwise comparison of attributes (i.e. paired t-test), hypothesized relationship between attitude, subjective norms, perceived behavior and purchase intentions (i.e. structural equation model) and relationship between perceived attributes and attitude towards the product (i.e. correlation analysis). The results are summarized as under.

\subsection{Factor analysis}

Factor analysis of each variable showed the construct validity of the variables (Comery and Lee, 1992). The KMO and Bartlett's test was used to predict the factorial structure between items. The results indicate a total variation between .019 and .082 as compared to the suggested threshold limit of .0 to 1.0.

The PCA was adopted for item reduction and Varimax rotation was applied to increase the variance between factors. The eigenvalues technique (see figure 4) for factor extraction shows a total of 07 extracted factors having eigenvalues 


\section{W. Rizvi et al}

greater than 1.0. The total variance of factors stood at $76.94 \%$ and $44.69 \%$, respectively. The KMO result in table 3 also specifies the sampling adequacy which was $95.7 \%$ and $89.4 \%$ greater than the required limit of $60 \%$ (Hair et al., 2010).

Table 3: KMO and Bartlett's Test

\begin{tabular}{llr}
\hline Kaiser-Meyer-Olkin measure of sampling adequacy & 0.96 \\
\hline \multirow{3}{*}{ Bartlett's Test of sphericity } & Approx. Chi-Square & 13347.43 \\
& Df & 1275 \\
& Sig. & 0.00
\end{tabular}

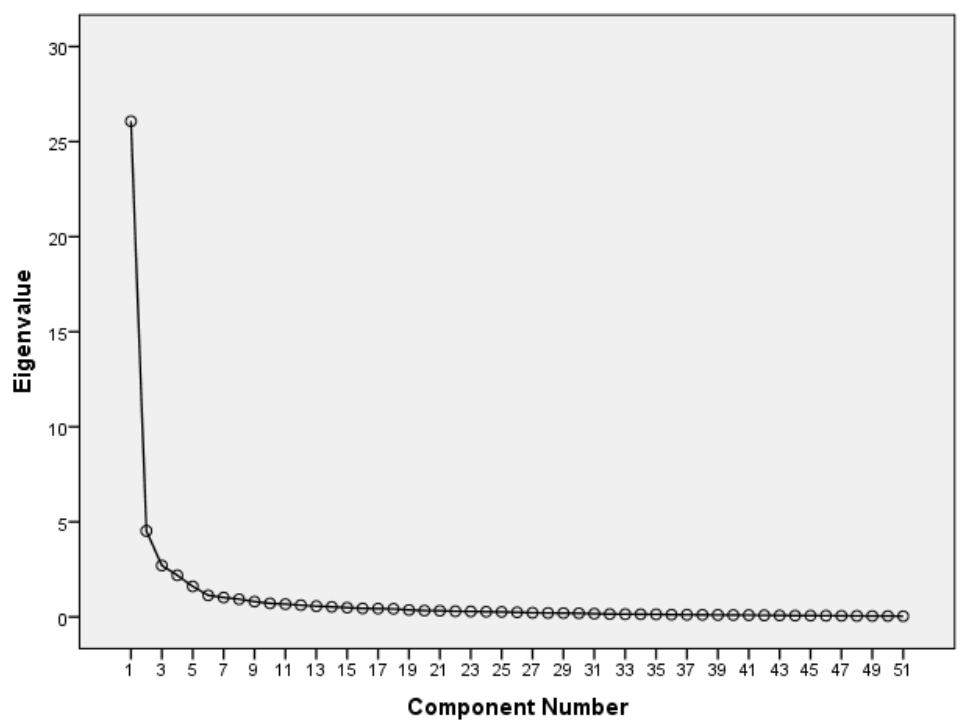

Fig 4: Screen plot

\subsection{Reliability}

Table 4 is a summary of the results of internal-consistency and reliability of the constructs based on the correlating responses to each item in the survey (Saunders et al., 2009). The Chronbach Alpha values of all the constructs including attributes, attitude, subjective norms, perceived behavioral control, and purchase intentions appeared reliable as all of these were found above the threshold limit of 0.7 (Nunnally and Bernstein, 1994). 
Enhanced understanding of purchase intentions...

Table 4: Reliability

\begin{tabular}{lccccc}
\hline \multicolumn{1}{c}{ Scale } & N of Items & Mean & Variance & Std. Deviation & Cronbach's Alpha \\
\hline Attributes (Swift) & 11 & 65.18 & 642.803 & 25.354 & 0.972 \\
Attributes (Vitz) & 11 & 72.34 & 739.982 & 27.203 & 0.979 \\
Attitude & 5 & 26.63 & 22.069 & 4.698 & 0.772 \\
Subjective norms & 4 & 6.365 & 18.98 & 40.513 & 0.864 \\
Perceived behaviour & 3 & 14.06 & 20.557 & 4.534 & 0.754 \\
Purchase intention & 4 & 17.04 & 36.51 & 6.042 & 0.918 \\
\hline
\end{tabular}

3.5 SEM based on attitude, subjective norms, perceived behavior, and purchase intentions

The SEM analysis was used in IBM-AMOS to categorize, calculate, and epitomize the hypothesized relationships in the model. For this, a set of normally distributed data was processed to yield a model fit. Figure 5 shows the hypothesized model based on hypothesis H1, H2, and H3. The structural relationship between subjective norms and purchase intention $(\mathrm{PI} \leftarrow \mathrm{SN}$ : $=0.096, \mathrm{t}=1.825$, $\mathrm{p}$-value $=0.068$ ) was found to be non-significant at $\mathrm{p}$-value $<0.05$. However, in case of hypothesis $\mathrm{H} 2$ and $\mathrm{H} 3$, the structural relationship between attitude and purchase intention $(\mathrm{PI} \leftarrow \mathrm{AT}:=0.369, \mathrm{t}=4.060, \mathrm{p}$-value $=0.001)$ and relationship between and perceived behavior and purchase intention ( $\mathrm{PI} \leftarrow \mathrm{PB}$ : $=0.832, \mathrm{t}=9.010, \mathrm{p}$-value $=0.001)$ was found to be significant at $\mathrm{p}$-value $<$ 0.05 .

The significant result of $\mathrm{H} 2$ and $\mathrm{H} 3$, infers that attitude and perceived behavior increase purchase intention. However, subjective norms have no impact on purchase intention. The model fit estimates indicate that the $\chi^{2}=326.688$, $\chi^{2} / \mathrm{df}=326.688 / 101=1.91, \mathrm{CFI}=0.983, \mathrm{TLI}=0.943, \mathrm{IFI}=0.921, \mathrm{NFI}$ $=0.942$, and RMSEA $=0.011$ represent a better fit than the recommended threshold limits.

Table 5: Maximum likelihood estimates and regression weights based on hypothesis H2, H3, and $\mathrm{H} 4$

\begin{tabular}{lcccc}
\hline \multicolumn{1}{c}{ Hypothesized Paths } & Estimate & S.E. & t - value & P \\
\hline Purchase intention $\leftarrow$ Subjective norms & 0.096 & 0.052 & 1.825 & 0.068 \\
Purchase intention $\leftarrow$ Attitude & 0.369 & 0.091 & 4.06 & $* * *$ \\
Purchase intention $\leftarrow$ Perceived behaviour & 0.832 & 0.092 & 9.01 & $* * *$ \\
\hline
\end{tabular}

3.6 Perceived attributes of a product positively affects attitude towards the product

SEM analysis was conducted to examine the hypothesized relationship between perceived attributes (Vitz) and attitude towards the product. A set of normally distributed data shows the hypothesized model based on hypothesis H4. The structural relationship between perceived attributes (Vitz) and attitude (Attitude $\leftarrow$ Perceived attributes: $=0.196, \mathrm{t}=7.320, \mathrm{p}$-value $=0.000)$ was found 


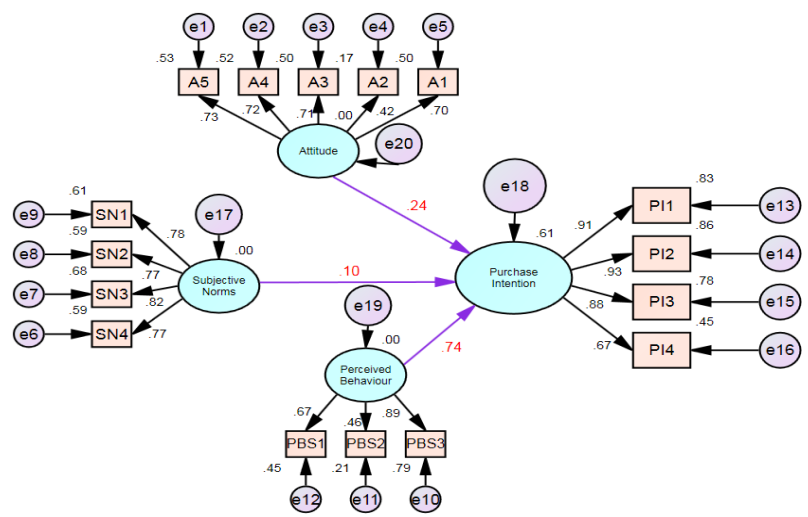

\section{Model Fit Results:}

Number of distinct sample moments: 153

Number of distinct parameters to be estimated: 52

Chi-square $=326.688$

Degrees of freedom $=101$

Chi-square $/ \mathrm{df}=326.688 / 171=1.91$

Probability level $=.000$

Baseline Comparisons: $\mathrm{CFI}=0.983, \mathrm{TLI}=0.943, \mathrm{IFI}=0.921, \mathrm{RFI}=0.897, \mathrm{NFI}=0.942$

RMSEA $=0.011$

Fig 5: Attitude, subjective norms, perceived behavior, and purchase intentions

to be significant at $\mathrm{p}$-value $<0.05$.

The significant result of $\mathrm{H} 4$, infers that perceived favorable attributes (Vitz) improve attitude towards the product. The model fit estimates indicate that the $\chi^{2}=491.631, \chi^{2} / \mathrm{df}=491.631 / 203=2.42, \mathrm{CFI}=0.902$, TLI $=0.871$, $\mathrm{IFI}=0903, \mathrm{NFI}=0.842$, and RMSEA $=0.0301$ represent a better fit than the recommended threshold limits.

\subsection{Impact of attributes (Vitz) on purchase intention}

SEM analysis was conducted to examine the hypothesized relationship between attributes (Vitz) and purchase intention. A set of normally distributed data shows the hypothesized model based on hypothesis H5. The structural relationship between attributes (Vitz) and purchase intention (PI $\leftarrow$ Total Attributes: $=0.239, \mathrm{t}=6.004, \mathrm{p}$-value $=0.000)$ was found to be significant at $\mathrm{p}$-value $<$ 0.05 .

The significant result of $\mathrm{H} 5$, infers that the presence of favorable attributes of Vitz increases purchase intention. The model fit estimates indicate that the $\chi^{2}=381.813, \chi^{2} / \mathrm{df}=381.813 / 143=2.67, \mathrm{CFI}=0.932$, TLI $=0.920$, IFI $=0.932$, NFI $=0.913$, and RMSEA $=0.0132$ represent a better fit than the recommended threshold limits. 
Enhanced understanding of purchase intentions...

Table 6: Standardized regression weights and squared multiple correlations

\begin{tabular}{|c|c|c|}
\hline Paths & $\begin{array}{l}\text { Standardized regression } \\
\text { weights }\end{array}$ & $\begin{array}{l}\text { Squared multiple cor- } \\
\text { relations }\end{array}$ \\
\hline Purchase intention $\leftarrow$ Subjective norms & 0.099 & 0.009 \\
\hline Purchase intention $\leftarrow$ Attitude & 0.237 & 0.056 \\
\hline Purchase intention $\leftarrow$ Perceived behaviour & 0.739 & 0.546 \\
\hline A $5 \leftarrow$ Attitude & 0.728 & 0.529 \\
\hline A $4 \leftarrow$ Attitude & 0.719 & 0.516 \\
\hline A $3 \leftarrow$ Attitude & 0.71 & 0.504 \\
\hline $\mathrm{A} 2 \leftarrow$ Attitude & 0.417 & 0.173 \\
\hline A1 $\leftarrow$ Attitude & 0.705 & 0.497 \\
\hline SN4 $\leftarrow$ Subjective norms & 0.768 & 0.589 \\
\hline SN3 $\leftarrow$ Subjective norms & 0.823 & 0.677 \\
\hline SN2 $\leftarrow$ Subjective norms & 0.765 & 0.585 \\
\hline SN1 $\leftarrow$ Subjective norms & 0.779 & 0.606 \\
\hline PBS3 $\leftarrow$ Perceived behaviour & 0.887 & 0.786 \\
\hline PBS2 $\leftarrow$ Perceived behaviour & 0.462 & 0.213 \\
\hline PBS1 $\leftarrow$ Perceived behaviour & 0.674 & 0.454 \\
\hline PI1 $\leftarrow$ Purchase intention & 0.912 & 0.831 \\
\hline PI $\leftarrow$ Purchase intention & 0.928 & 0.861 \\
\hline PI3 $\leftarrow$ Purchase intention & 0.881 & 0.776 \\
\hline PI $4 \leftarrow$ Purchase intention & 0.667 & 0.445 \\
\hline
\end{tabular}

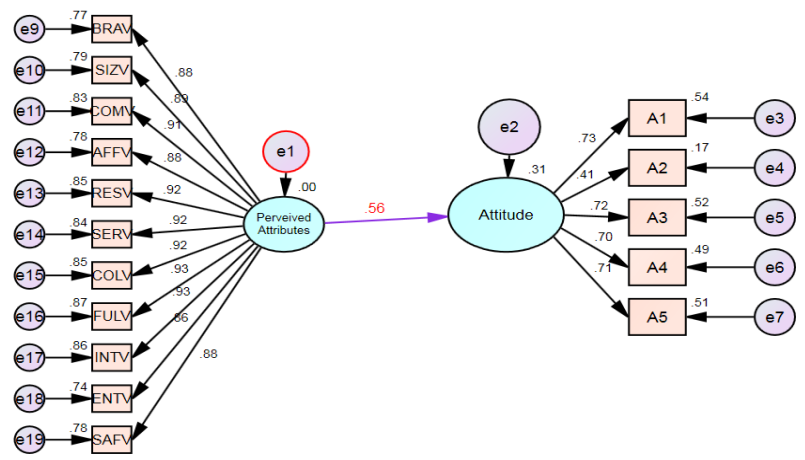

Model Fit Results:

Number of distinct sample moments: 252

Number of distinct parameters to be estimated: 49

Chi-square $=491.631$

Degrees of freedom $=203$

Chi-square/df $=491.631 / 203=2.42$

Probability level $=.000$

Baseline Comparisons: $\mathrm{CFI}=0.902, \mathrm{TLI}=0.871, \mathrm{IFI}=0.903, \mathrm{RFI}=0.842, \mathrm{NFI}=0.880$

RMSEA $=0.0301$

Fig 6: Perceived attributes of a product and attitude towards the product

3.8 Paired comparison between perceived attributes of a product and attitude towards the product

Table 9 summarizes the results of comparative analysis using paired comparison in SPSS. A total of eleven attributes of Toyota Vitz and Suzuki Swift were

Business Review: (2018) 13(1):52-68 


\section{W. Rizvi et al}

Table 7: Maximum likelihood estimates and regression weight based on hypothesis H4

\begin{tabular}{ccccc}
\hline Hypothesized Paths & Estimate & S.E. & t - value & P \\
\hline Attitude $\leftarrow$ Perceived attributes VITZ & 0.196 & 0.027 & 7.32 & $* * *$ \\
\hline
\end{tabular}

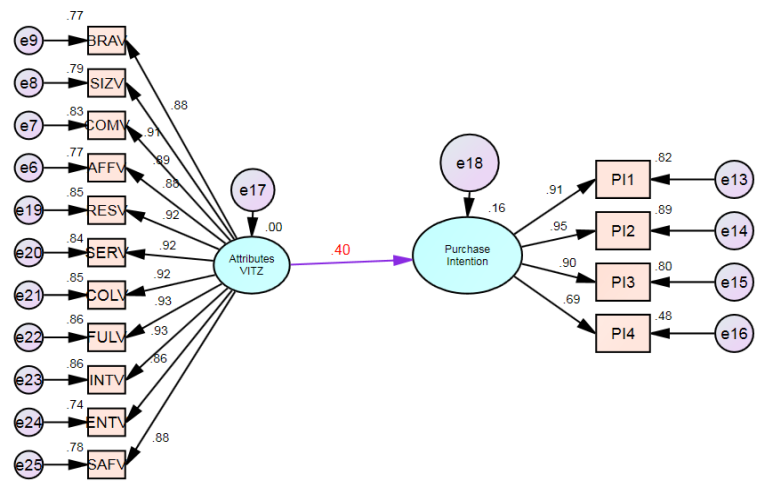

Model Fit Results:

Number of distinct sample moments: 189

Number of distinct parameters to be estimated: 46

Chi-square $=381.813$

Degrees of freedom $=143$

Chi-square $/ \mathrm{df}=381.813 / 143=2.67$

Probability level $=.000$

Baseline Comparisons: $\mathrm{CFI}=0.932, \mathrm{TLI}=0.920, \mathrm{IFI}=0.932, \mathrm{RFI}=0.898, \mathrm{NFI}=0.913$ RMSEA $=0.0132$

Fig 7: Attributes (VITZ) and purchase intention

Table 8: Maximum Likelihood estimates and regression weights based on hypothesis H5

\begin{tabular}{ccccc}
\hline Hypothesized paths & Estimate & S.E. & t - value & $\mathrm{P}$ \\
\hline Purchase intention $\leftarrow$ Attributes Vitz & 0.239 & 0.04 & 6.004 & $* * *$ \\
\hline
\end{tabular}

compared on the basis of significant difference. According to the results, there is a significant difference between Swift and Vitz with respect to brand name, price/affordability, comfort level, entertainment features, interior, safety and fuel efficiency. $\quad 3$ attributes i.e. size, serviceability, and color were found to be non-significantly different from each other. It was also observed from the mean values that people prefer Vitz over Swift on some attributes. In addition, Vitz is close to the hatchback category line in terms of perceived attributes and people have shown greater preference for Vitz than the Swift.

\subsection{Perceived attribute importance: Brand comparative analysis}

Further comparative analysis was conducted on Swift and Vitz with respect to perceived importance of each elicited attribute. Table 10 shows mean scores of each attribute in terms of its importance, to show low and high scores (of each attribute) the mean score of each attribute related to a brand was subtracted 
Enhanced understanding of purchase intentions...

Table 9: Pair-wise attributes (Paired t test)

\begin{tabular}{lccccc}
\hline \multirow{2}{*}{ Pair-wise attributes Vitz - Swift } & Mean diff & \multicolumn{2}{c}{$95 \%$ Conf int of the diff } & t & Sig \\
& & Lower & Higher & & \\
\hline Brand name & 1.24 & 0.94 & 1.54 & 8.22 & $\mathrm{P}<.01$ \\
Size & 0.12 & -0.14 & 0.39 & 0.92 & $\mathrm{P}>.05$ \\
Comfort & 0.51 & 0.24 & 0.79 & 3.74 & $\mathrm{P}<.01$ \\
Affordability & 0.5 & 0.23 & 0.76 & 3.71 & $\mathrm{P}<.01$ \\
Resale & 0.48 & 0.2 & 0.76 & 3.38 & $\mathrm{P}<.01$ \\
Serviceability & 0.42 & 0.15 & 0.69 & 3.12 & $\mathrm{P}<.01$ \\
Color & 0.31 & 0.08 & 0.53 & 2.68 & $\mathrm{P}<.01$ \\
Fuel-efficiency & 0.82 & 0.52 & 1.11 & 5.48 & $\mathrm{P}<.01$ \\
Interior & 0.73 & 0.47 & 1 & 5.52 & $\mathrm{P}<.01$ \\
Entertain-features & 1.02 & 0.72 & 1.32 & 6.79 & $\mathrm{P}<.01$ \\
Safety & 0.96 & 0.69 & 1.24 & 6.85 & $\mathrm{P}<.01$ \\
\hline
\end{tabular}

from perceived importance of the respective attribute. In the last column mean scores of Swift have been subtracted from mean attribute scores of Vitz .

Table 10: Car category attribute importance gap \& brand attribute comparison

\begin{tabular}{|c|c|c|c|c|}
\hline Car Category & AI (Mean) & Swift (Suzuki) PA - AI & Vitz (Toyota) PA - AI & Vitz-Swift \\
\hline Brand name & 6.83 & $5.736 .83=-1.1$ & $6.976 .83=0.13$ & $6.975 .73=1.24$ \\
\hline Size & 6.59 & $6.356 .59=-0.25$ & $6.476 .59=-0.11$ & $6.476 .35=0.12$ \\
\hline Comfort & 7.2 & $6.27 \quad 7.20=-0.93$ & $6.78 \quad 7.20=-0.41$ & $6.78 \quad 6.27=0.51$ \\
\hline Affordability & 7.21 & $5.747 .21=-1.46$ & $6.247 .21=-0.96$ & $6.245 .74=0.50$ \\
\hline Resale & 7.03 & $5.967 .03=-1.06$ & $6.457 .03=-0.58$ & $6.465 .96=0.48$ \\
\hline Serviceability & 7.2 & $6.107 .20=-1.09$ & $6.537 .20=-0.67$ & $6.536 .10=0.43$ \\
\hline Color & 6.08 & $6.016 .08=-0.07$ & $6.326 .08=0.23$ & $6.326 .01=0.31$ \\
\hline Fuel efficiency & 7.43 & $5.867 .43=-1.57$ & $6.687 .43=-0.75$ & $6.685 .86=0.81$ \\
\hline Interior & 6.73 & $5.816 .73=-0.91$ & $6.556 .73=-0.18$ & $6.555 .81=0.73$ \\
\hline Entertain-features & 6.19 & $5.466 .19=-0.72$ & $6.496 .19=-0.30$ & $6.495 .46=1.02$ \\
\hline Safety & 7.44 & $5.907 .44=-1.57$ & $6.867 .44=-0.57$ & $6.865 .90=0.96$ \\
\hline
\end{tabular}

\section{Conclusion and managerial implications}

Predictability of purchase intentions is of prime importance for long term sustainability of an organization because of its positive association with actual behavior. This, however, can be challenging and, thus, requires proper model specification and understanding of appropriate factors that can lead to purchase intentions. The process can be further complicated if purchase behavior is targeted towards high involvement products that require systematic decision making rather than heuristic thought processes.

The results of the specified model (theory of planned behavior) in the context of car buying suggest that attitude, subjective norms, and behavioral control have positive influence on purchase intentions. Comparatively, behavioral control has greater influence than attitude and subjective norms. The model offers substantial explanation in purchase intentions (.61\%) for car purchasing. The results of this study are consistent with earlier studies conducted in this context 


\section{W. Rizvi et al}

(Moons and De Pelsmacker 2015).

This study also probes further to identify the most desired product attributes that influence attitude and purchase intentions. Results based on qualitative data identified eleven attributes: comfort level (material), brand name, affordability, resale value, serviceability (parts availability), color, fuel efficiency, interior, entertainment features and safety features. Results from quantitative analysis suggest that product attributes influence attitude and purchase intentions. Similarly, in context of car buying Altaf et al (2017) found influence of functional value on attitude towards car buying. Although customized elicited attributes are not necessarily reflective of exact functional value, it does reflect the utilitarian aspect and its influence on brand attitude.

The results of the comparative analysis using the eleven attributes provide evidence that there is significant difference between Vitz and Swift across elicited product attributes. Only one exception, the size of the car, was not significantly different. Overall respondents rated Vitz higher on all attributes as compared to Swift.

\subsection{Managerial implications}

This study highlights how components of theory of planned behavior function within the context of high involvement products, specifically in the context of car buying. The results suggest that for car purchase decisions, perceived behavioral control and attitude were main determinants of purchase intentions with coefficients of .74 and .24 respectively, whereas subjective norms showed lower influence with .11 coefficient. These results can help practitioners formulate their marketing efforts and communications.

In context of high involvement products practitioners are more interested in detailed product attributes and how consumers rate those specific attributes rather than just overall perceived quality. This study identifies major product attributes that may lead to positive attitude and consequently generate purchase intentions. It also provides a holistic comparative analysis between two brands. In practice, practitioners can evaluate their brands vis--vis their competitors and formulate proactive marketing strategies that take into account target market preferences and desired attributes.

\subsection{Research limitations}

Both qualitative and quantitative data collection processes were subject to certain limitations. In the quantitative study judgmental and continence (nonprobability) sampling was used. The use of this sampling technique limits the generalizability of the study. Similarly, in the qualitative study data was collected only from Karachi and only with one filter (driving expertise). This also limits the appropriateness of the elicited attributes.

Furthermore as this was an initial study, the impact of all elicited attributes on attitude and purchase intentions was assessed. The research can be further 
Enhanced understanding of purchase intentions...

refined by far reaching data collection across Pakistan and weighting of the elicited attributes to observe the comparative effects of different attribute sets.

\section{References}

Ajzen I (1985) From intentions to actions: A theory of planned behavior. In: Action control, Springer, pp 11-39

Ajzen I (1991) The theory of planned behavior. Organizational behavior and human decision processes 50(2):179-211

Ajzen I, Fishbein M (1970) The prediction of behavior from attitudinal and normative variables. Journal of experimental social Psychology 6(4):466-487

Al-Swidi A, Mohammed Rafiul Huque S, Haroon Hafeez M, Noor Mohd Shariff M (2014) The role of subjective norms in theory of planned behavior in the context of organic food consumption. British Food Journal 116(10):1561-1580

Altaf SN, Perumal S, Hussin Z (2017) Consumption values and consumer attitude towards automobile purchase. Paradigms 11(1):1

Armitage CJ, Conner M (2001) Efficacy of the theory of planned behaviour: A meta-analytic review. British journal of social psychology 40(4):471-499

Arvola A, Vassallo M, Dean M, Lampila P, Saba A, Lähteenmäki L, Shepherd R (2008) Predicting intentions to purchase organic food: The role of affective and moral attitudes in the theory of planned behaviour. Appetite 50(2-3):443-454

Biel A, Thøgersen J (2007) Activation of social norms in social dilemmas: A review of the evidence and reflections on the implications for environmental behaviour. Journal of economic psychology 28(1):93-112

Boateng H, Okoe AF (2015) Consumers attitude towards social media advertising and their behavioural response: The moderating role of corporate reputation. Journal of Research in Interactive Marketing 9(4):299-312

Brown M, Pope N, Voges K (2003) Buying or browsing? an exploration of shopping orientations and online purchase intention. European Journal of Marketing 37(11/12):1666-1684

Chaniotakis IE, Lymperopoulos C, Soureli M (2010) Consumers' intentions of buying ownlabel premium food products. Journal of Product \& Brand Management 19(5):327-334

Chen MF (2007) Consumer attitudes and purchase intentions in relation to organic foods in taiwan: Moderating effects of food-related personality traits. Food Quality and preference 18(7):1008-1021

Chen MF, Tung PJ (2014) Developing an extended theory of planned behavior model to predict consumers intention to visit green hotels. International journal of hospitality management 36:221-230

Dean M, Raats MM, Shepherd R (2012) The role of self-identity, past behavior, and their interaction in predicting intention to purchase fresh and processed organic food1. Journal of Applied Social Psychology 42(3):669-688

Eagly AH, Chaiken S (1993) The psychology of attitudes. Harcourt Brace Jovanovich College Publishers

Fazio RH (1990) Multiple processes by which attitudes guide behavior: The mode model as an integrative framework. In: Advances in experimental social psychology, vol 23, Elsevier, pp 75-109

Fishbein M, Ajzen I (1975) Belief, attitude, intention and behavior: An introduction to theory and research

Godin G, Kok G (1996) The theory of planned behavior: a review of its applications to health-related behaviors. American journal of health promotion 11(2):87-98

Gracia Royo A, Magistris Td (2007) Organic food product purchase behaviour: a pilot study for urban consumers in the south of italy

Ham M, Jeger M, Frajman Ivković A (2015) The role of subjective norms in forming the intention to purchase green food. Economic research-Ekonomska istraživanja 28(1):738748

Han H, Hsu LTJ, Sheu C (2010) Application of the theory of planned behavior to green hotel choice: Testing the effect of environmental friendly activities. Tourism management 31(3):325-334

Business Review: (2018) 13(1):52-68 


\section{W. Rizvi et al}

Jayaraman K, Yun WW, Seo YW, Young H (2018) Customers reflections on the intention to purchase hybrid cars: an empirical study from malaysia

Kinnear TC, Taylor JR (1996) Marketing research: An applied research. USA: McGrawhill

Kotchen MJ, Reiling SD (2000) Environmental attitudes, motivations, and contingent valuation of nonuse values: a case study involving endangered species. Ecological Economics 32(1):93-107

Laroche M, Kim C, Zhou L (1996) Brand familiarity and confidence as determinants of purchase intention: An empirical test in a multiple brand context. Journal of business Research 37(2):115-120

Lebeau K, Van Mierlo J, Lebeau P, Mairesse O, Macharis C (2012) The market potential for plug-in hybrid and battery electric vehicles in flanders: A choice-based conjoint analysis. Transportation Research Part D: transport and environment 17(8):592-597

Lee D, Trail GT (2012) Confirmatory analysis of the athletic team merchandise model. Measurement in Physical Education and Exercise Science 16(2):101-118

Moons I, De Pelsmacker P (2012) Emotions as determinants of electric car usage intention. Journal of Marketing Management 28(3-4):195-237

Moons I, De Pelsmacker P (2015) An extended decomposed theory of planned behaviour to predict the usage intention of the electric car: A multi-group comparison. Sustainability $7(5): 6212-6245$

Morwitz V, et al (2014) Consumers' purchase intentions and their behavior. Foundations and Trends $($ in Marketing 7(3):181-230

Povey R, Conner M, Sparks P, James R, Shepherd R (2000) The theory of planned behaviour and healthy eating: Examining additive and moderating effects of social influence variables. Psychology \& Health 14(6):991-1006

Ramayah T, Lee JWC, Lim S (2012) Sustaining the environment through recycling: An empirical study. Journal of environmental management 102:141-147

Rimal A, Fletcher SM, McWatters K, Misra SK, Deodhar S (2001) Perception of food safety and changes in food consumption habits: a consumer analysis. International Journal of Consumer Studies 25(1):43-52

Rosenberg MJ (1956) Cognitive structure and attitudinal affect. The Journal of abnormal and social psychology 53(3):367

Schuitema G, De Groot JI (2015) Green consumerism: The influence of product attributes and values on purchasing intentions. Journal of Consumer Behaviour 14(1):57-69

Sheppard BH, Hartwick J, Warshaw PR (1988) The theory of reasoned action: A meta-analysis of past research with recommendations for modifications and future research. Journal of consumer research 15(3):325-343

Sparks P, Shepherd R (1992) Self-identity and the theory of planned behavior: Assesing the role of identification with" green consumerism". Social psychology quarterly pp 388-399

Sutton RS, Barto AG, et al (1998) Reinforcement learning: An introduction. MIT press

Tarkiainen A, Sundqvist S (2005) Subjective norms, attitudes and intentions of finnish consumers in buying organic food. British food journal 107(11):808-822

Taylor S, Todd PA (1995) Understanding information technology usage: A test of competing models. Information systems research 6(2):144-176

Terry DJ, O'Leary JE (1995) The theory of planned behaviour: The effects of perceived behavioural control and self-efficacy. British journal of social psychology 34(2):199-220

Vermeir I, Verbeke W (2006) Sustainable food consumption: Exploring the consumer attitudebehavioral intention? gap. Journal of Agricultural and Environmental ethics 19(2):169-194

Wang S, Fan J, Zhao D, Yang S, Fu Y (2016) Predicting consumers intention to adopt hybrid electric vehicles: using an extended version of the theory of planned behavior model. Transportation 43(1):123-143

White Baker E, Al-Gahtani SS, Hubona GS (2007) The effects of gender and age on new technology implementation in a developing country: Testing the theory of planned behavior (tpb). Information Technology \& People 20(4):352-375 